\title{
DYNAMIC RESPONSE OF A 190M-HIGH TRANSMISSION TOWER FOR A LARGE RIVER CROSSING
}

\author{
Leandro Fleck FADEL MIGUEL ${ }^{\mathrm{a}}$, João KAMINSKI Jr. ${ }^{\mathrm{b}}$, Letícia Fleck Fadel MIGUEL ${ }^{\mathrm{c}}$, \\ Jorge Daniel RIERA ${ }^{\mathrm{d}}$, Ruy Carlos Ramos de MENEZES ${ }^{\mathrm{d}}$ \\ ${ }^{a}$ Department of Civil Engineering, Federal University of Santa Catarina, Florianópolis, Brazil \\ ${ }^{b}$ Department of Civil Engineering, Federal University of Santa Maria, Santa Maria, Brazil \\ ${ }^{c}$ Department of Mechanical Engineering, Federal University of Rio Grande do Sul, Porto Alegre, Brazil \\ ${ }^{d}$ Department of Civil Engineering, Federal University of Rio Grande do Sul, Porto Alegre, Brazil
}

Received 28 Feb 2013; accepted 04 Jun 2013

\begin{abstract}
The construction of a double circuit 500kV transmission line (TL) in the Brazilian Amazon region is currently in progress. In addition to its length within the rain forest, the TL had to overcome large river crossings and environmental constrains. Among them, the crossing of the Trombetas River is one of the most important, with a total length of more than $5100 \mathrm{~m}$. The proposed design includes two $190 \mathrm{~m}$ high towers necessary to attain spans as long as $1600 \mathrm{~m}$. Additionally, the towers had to be supported by concrete columns, $10 \mathrm{~m}$ above ground level, due to the annual flooding of the river bed. These structures demand a detailed assessment, since the design required long-span conductors and tall structures that are outside the range normally considered in codes. In this context, the present article describes the dynamic analysis of the complete TL segment for this crossing, with emphasis on the response of the $190 \mathrm{~m}$-high main structure which is subjected to Extended Pressure Systems and Thunderstorm wind loads, as well as cable rupture. The entire TL crossing is modelled, including the two highest towers and all other elements. The responses determined by such approach are then compared to values obtained by standard practice.
\end{abstract}

Keywords: transmission line crossing structures, wind loads, cable rupture, model uncertainty.

\section{Introduction}

In the last three decades, dynamic effects on transmission lines have been studied by different authors (Matheson, Holmes 1981; Alam, Santhakumar 1994; Oliver et al. 2000; Li 2000; Savory et al. 2001, 2008; Loredo-Souza, Davenport 2003; Shehata et al. 2005; Kudzys 2006; Paluch et al. 2007; Lin et al. 2012; Miguel et al. 2012), confirming that this subject is not fully addressed and still deserves attention.

Although these studies have shown that the simplified static-equivalent approaches, typically adopted for the design of TL structures, are appropriate for conventional designs (Matheson, Holmes 1981; Alam, Santhakumar 1994; Loredo-Souza, Davenport 2003; Miguel et al. 2012), scarce information is available for the structures and span dimensions adopted in the crossing of the Trombetas River, which are outside the scope of TL codes (e.g. IEC $60826-2003$ considers spans between 200 and 800 $\mathrm{m}$ and towers up to $60 \mathrm{~m}$ high). Moreover, design requirements for winds associated to localized events such as thunderstorms (TS) winds just begun recently to be specifically considered in TL wind design. The few available references (Oliver et al. 2000; Li 2000; Savory et al. 2001; Shehata et al. 2005) focus attention, once again, on conventional towers with heights below $60 \mathrm{~m}$.

Thus, the necessity for further evaluations is clear. The resulting information should be useful to designers of large TL towers, since both code specifications and literature available are not applicable to exceptionally tall towers.

Within this context, this paper aims at the determination of the dynamic behaviour, caused by different excitations, of a special crossing steel tower in the Brazilian Amazon region. The studies were carried out through modelling and analysis of the entire transmission line segment (towers, cables and insulator strings), representing cables and structures by means of truss elements and solving the resulting equations of motion by direct explicit numerical integration, using central finite differences. In this approach geometrical non linearity is naturally considered, thus accounting for large displacements and the possibility of global instability or of rupture of any of the components.

Corresponding author: Leandro Fleck Fadel Miguel

E-mail: leandro.miguel@ufsc.br 
In order to numerically simulate Extended Pressure System (EPS) winds, which are modelled as a horizontal air flow, with uniform mean velocity and orientation throughout a large region, it is admitted that the wind field can be described by a stationary and homogeneous 3D turbulent flow. The wind turbulence is defined by the spectra of the two horizontal and the vertical fluctuating velocity components, which are usually assumed independent random processes, as described in Section 2.1. The model described above constitutes a reasonable approximation for EPS winds, characteristic of both extra-tropical and tropical storm winds, but it is not applicable for thunderstorm (TS) winds. In this study, these storms were simulated employing the model proposed by Ponte and Riera $(2007,2010)$, as described in Section 2.2.

In addition, the structural response due to cable rupture is also simulated. Modelling of the complete TL segment allows the assessment of important factors that are not considered in usual practice, such as the influence of the remaining cables in case of rupture of a bundled conductor as well as the redistribution of the internal forces when the collapse of an adjacent component occurs. Thus, an important additional contribution of the paper consists of the numerical evaluation of the behaviour of a TL segment subjected to cable rupture.

Finally, since the base of the towers is built on concrete columns $10 \mathrm{~m}$ above terrain level, founded on soils with low carrying capacity, the influence on the response of the flexibility of the foundations was also evaluated during design. Three different models of the foundations were examined: rigid, semi-rigid and floating foundations. Peak values of the axial member forces for all cases are compared with the response obtained through conventional TL design methods. Additionally, the spectral properties of the GTS 01 tower were determined through a set of FEM models and a comprehensive study assessing model uncertainty on response was carried out.

\section{Description of the crossing and the structural system}

\subsection{Crossing on the Trombetas River}

The crossing TL over the Trombetas River is composed of anchor towers at both ends (GTA 00 and GTA 01) and a central section with three suspension towers (GTS 00, GTS 01 and GTS 02), as shown in Figure 1. Details of the tower GTS 01 can be seen in Figure 6 of Section 4.

The main spans of the Trombetas River crossing design are $1598 \mathrm{~m}$ and $1590 \mathrm{~m}$ long, while the suspension towers should have useful heights equal to $190 \mathrm{~m}$ and $119 \mathrm{~m}$. Two towers (GTS 00 and GTS 01) have their foundations about $10 \mathrm{~m}$ above dry ground level, due to the elevation of the river level during the flooding season (Menezes et al. 2012).

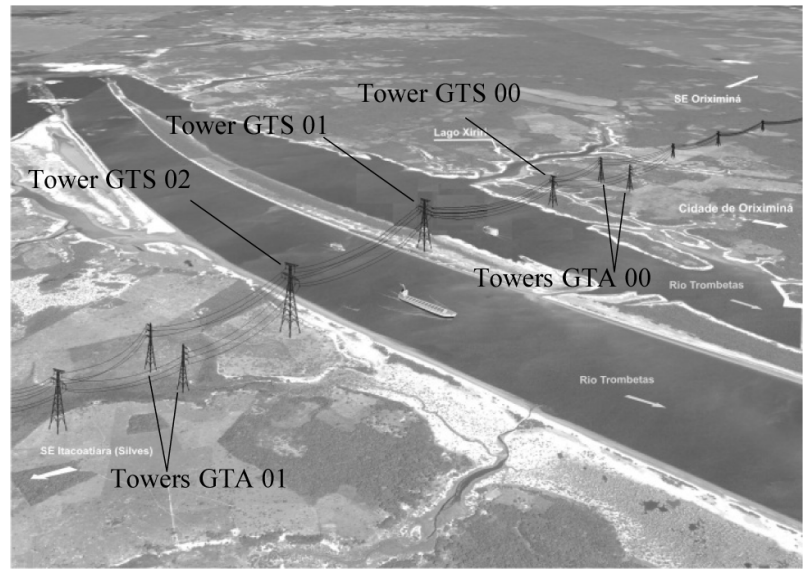

Fig. 1. View of the crossing over the Trombetas River

\subsection{General considerations}

Direct explicit numerical integration of the equations of motion in the time domain is adopted, using the finite central differences scheme, because it does not require assembling or updating the system global stiffness matrix. Integration is accomplished at elements level, which constitutes an advantage in nonlinear problems. Additional details about this integration method applied to dynamic analysis of TL towers and cables can be found in Miguel et al. (2005), Kaminski et al. (2005, 2008), and Kaminski (2007).

The tower selected (GTS 01) to provide spectral properties as well as for monitoring axial forces and top displacements is identified in Figure 1. The aerodynamic coefficients were determined following the procedure defined by IEC 60826 (2003). Regarding structural damping, it is known that energy dissipation in steel lattice towers increases with the vibration amplitude. Limited experimental evidence suggests critical damping ratios around $10 \%$ for large response amplitudes (Silva et al. 1984). Hence in the dynamic simulations reported herein, the suggested mean $10 \%$ value was adopted.

\subsection{Modal analysis of the GTS 01 Tower}

Before performing the dynamic analysis of the TL segment, a modal analysis of a FEM model of GTS 01 isolated tower was carried out, in order to determine its spectral properties separately, i.e. without cables and insulators. The sensitivity of the results to variations of the parameters was carefully evaluated (Silva et al. 2005). To assess the influence of mass distribution, foundation flexibility and type of element on the first six frequencies and modes, twelve models were analysed. The first six natural frequencies and vibration modes are presented in Table 1. For a more convenient comparison, the following symbols are employed: (1) 3D-Truss element (T), 3D-Beam element (B), 3D-Truss and beams elements (TB); (2) the presence of the elevated foundation (10 m-high concrete columns) is indicated by (EW) and its absence by (EWO); (3) the presence of additional 
Table 1. First six natural frequencies and mode shapes of the tower GTS 01

\begin{tabular}{|c|c|c|c|c|c|c|}
\hline \multirow[b]{2}{*}{ MODEL } & \multicolumn{6}{|c|}{ Natural Frequencies of Vibration $(\mathrm{Hz})$} \\
\hline & $\begin{array}{c}1^{\text {st }} \text { Bending Mode - } \\
\text { X-direction }\end{array}$ & $\begin{array}{c}1^{\text {st }} \text { Bending Mode - } \\
\text { Z-Direction }\end{array}$ & $\begin{array}{l}1^{\text {st }} \text { Torsion } \\
\text { Mode }\end{array}$ & $\begin{array}{c}2^{\text {st }} \text { Bending } \\
\text { Mode - } \\
\text { X-direction }\end{array}$ & $\begin{array}{c}2^{\text {st }} \text { Bending } \\
\text { Mode - } \\
\text { Z-Direction }\end{array}$ & $\begin{array}{l}2^{\text {st }} \text { Torsion } \\
\text { Mode }\end{array}$ \\
\hline 01 (TB-EWO-MWO-RF) & 1.04 & 1.04 & 1.52 & 1.69 & 1.69 & 2.18 \\
\hline 02 (T-EWO-MWO-RF) & 1.04 & 1.05 & 1.56 & 1.70 & 1.71 & 2.41 \\
\hline 03 (TB-EW-MWO-RF) & 1.00 & 1.00 & 1.50 & 1.57 & 1.58 & 2.15 \\
\hline 04 (T-EW-MWO-RF) & 0.99 & 1.00 & 1.54 & 1.58 & 1.59 & 2.36 \\
\hline 05 (TB-EW-MWO-CF) & 0.86 & 0.86 & 1.48 & 1.47 & 1.48 & 2.12 \\
\hline 06 (T-EW-MWO-CF) & 0.86 & 0.87 & 1.51 & 1.47 & 1.49 & 2.32 \\
\hline 07 (TB-EWO-MW-RF) & 0.73 & 0.73 & 1.00 & 1.28 & 1.30 & 1.63 \\
\hline 08 (T-EWO-MW-RF) & 0.73 & 0.74 & 1.02 & 1.28 & 1.30 & 1.65 \\
\hline 09 (TB-ES-MW-CF) & 0.65 & 0.65 & 0.99 & 1.10 & 1.12 & 1.56 \\
\hline 10 (T-ES-MW-CF) & 0.62 & 0.62 & 1.01 & 1.09 & 1.11 & 1.57 \\
\hline 11 (TB-ES-MW-FF) & 0.31 & 0.31 & 0.83 & 0.82 & 0.82 & 1.23 \\
\hline 12 (T-ES-MW-FF) & 0.31 & 0.31 & 0.83 & 0.82 & 0.82 & 1.26 \\
\hline
\end{tabular}

masses (secondary bars, bolts, steel plates, galvanization and equipment) is indicated by (MW) and its absence by (MWO); and (4) the foundation type is indicated by: rigid (RF), conventional (CF) and floating (FF).

The coefficients used in the models to account for foundations flexibility are described in Section 1.4. $\mathrm{Ob}$ serve that in all cases the fundamental frequency was slightly superior to or even below $1 \mathrm{~Hz}$, range in which dynamic effects may be expected to be relevant. In addition, the mass distribution along the height and the flexibility of the various support types considered play important roles on the frequencies, causing variations that may reach $50 \%$.

\subsection{Influence of the foundation stiffness on the tower response}

During the design stage the available information on local geology presented large uncertainties, since detailed studies of the upper soils layers were not yet available. Additionally, due to the elevation of the river level during the flooding season, the bases of the steel towers GTS 00 and GTS 01 had to be about $10 \mathrm{~m}$ above ground level. Thus, the usual assumption of a rigid foundation was judged unsuitable.

To assess the influence of dynamic effects, predictions of the dynamic analysis of the towers on a rigid base were compared to those provided by a conventional static analysis. Next, simulations were carried out assuming (a) a foundation with a typical design and in addition; (b) a floating foundation.

In case (a) the foundation flexibility was determined for a tower with each leg supported by a $10 \mathrm{~m}$ high tubular concrete column with an external diameter of $2.50 \mathrm{~m}, 0.10 \mathrm{~m}$ wall thickness and Young's Modulus $E_{c}=25 \times 10^{3} \mathrm{MPa}$. The stiffness coefficients in both horizontal directions and in the vertical direction resulted equal to $k_{x}=k_{z}=4.08 \times 10^{7} \mathrm{~N} / \mathrm{m}$ and $k_{y}=4.08 \times 10^{8} \mathrm{~N} / \mathrm{m}$ respectively.
For case (b) a lower bound estimate of the vertical stiffness of a floating foundation with a base area of $100 \mathrm{~m}^{2}$, determined neglecting the contribution of the upper soft soil layers, led to $k_{y}=1.0 \times 10^{6} \mathrm{~N} / \mathrm{m}$, value that was considered unrealistically low. Consequently, lower bound estimates of the stiffness coefficients in the horizontal and vertical directions were determined as equal to $5 \%$ of the estimated stiffness for case (a). Note that these values were adopted before reliable field information on soil properties was available, i.e. before the foundation design, as a worst case condition.

The support reactions were evaluated through a full dynamic simulation, assuming that the coefficients indicated above define the foundation stiffness. Peak values observed in the dynamic simulations were compared with predictions of the static analysis, to establish maximum values to be used for the foundation design, which provided the final stiffness coefficients.

The final configuration of the tower foundations consists of $7.0 \times 7.0 \times 2.60 \mathrm{~m}$ concrete blocks, which are supported by nine inclined tubular metallic piles with $1.0 \mathrm{~m}$ external diameter and $0.125 \mathrm{~m}$ thickness. A FEM model of the tower was subjected to static gravity and wind loading by an independent firm that designed the foundations. This static analysis of a single tower led to the forces and corresponding displacements at the support nodes of the steel tower indicated in Table 2, which were used to establish equivalent stiffness coefficients for the elastic supports of the steel tower in the global model (Fig. 4). The stiffness coefficients in both horizontal directions resulted equal to $k_{x}=k_{z}=3.45 \times 10^{7} \mathrm{~N} / \mathrm{m}$. In the vertical direction, coefficients $k_{y}=3.983 \times 10^{9} \mathrm{~N} / \mathrm{m}$ for tension and $k_{y}=1.413 \times 10^{9} \mathrm{~N} / \mathrm{m}$ for compression were obtained. These coefficients apply to the entire foundation system, including the tubular concrete columns and account for soil properties as well as P-delta effects. In the numerical dynamic analysis, non-linear spring 
supports were introduced in the model. Note that the horizontal coefficients $k_{x}$ and $k_{z}$ were taken as the average between the values presented in Table 2 .

\subsection{Design procedure for cable rupture}

In the case of the crossing section on the Trombetas River, the conductor cables were designed for a tension equal to $22 \%$ of its capacity (UTS - Ultimate Tension Stress). Therefore, the magnitude of the load that should be applied on the GTS 01 tower, in the longitudinal direction, must be around $18 \%$ of its UTS, jointly with other relevant loads in the vertical direction due to dead weight of the tower, equipment, conductor cables that did not break and shield wires.

\section{Simulation of wind velocity fields}

\subsection{Synoptic winds (EPS storms)}

The procedure to generate the wind field adopted in the paper requires first the generation of uncorrelated wind velocity time histories for the specified psdf of the fluctuating velocity components. In a Cartesian coordinate system $(x, y, z)$, in which $z$ denotes height above the ground and $x$ the along-wind direction, the wind velocity is assumed to consist of a mean velocity vector $\overrightarrow{\vec{V}}(z)$ and a fluctuating component velocity vector $\Delta \vec{V}(x, y, z, t)$ which is assumed a stationary random vector process with zero mean:

$$
\vec{V}(x, y, z, t)=\overrightarrow{\bar{V}}(z)+\Delta \vec{V}(x, y, z, t) .
$$

The mean wind profile $\overrightarrow{\vec{V}}(z)$ is herein described using the classical logarithmic law. The fluctuating velocity components $\Delta \vec{V}(x, y, z, t)$ are zero-mean normal random processes simulated in this study by superposition of harmonic waves, as described by Shinozuka and Jan (1972). Several expressions for the power spectral density function $S_{w}$ of the longitudinal component of the fluctuating wind velocity are found in the literature. In this paper, Davenport's model (Davenport 1961) is considered.

Riera and Ambrosini (1992) proposed a very efficient scheme to generate a correlated random wind field for the dynamic analysis of tall vertical towers, based on the adoption of a triangular cross-correlation function. This approach was extended by Miguel et al. $(2009,2012)$ to two and three dimensions. In such cases the coordinates of nodes in a 2- or 3-D arrangement must be specified, such that the distance between nodes is given by the correlation length in each direction. Thus, in order to simulate the spatially correlated wind field, the correlation

Table 2. Force vs. displacements for design foundations

\begin{tabular}{ccccc}
\hline & \multicolumn{2}{c}{ Compression } & \multicolumn{2}{c}{ Tension } \\
\cline { 2 - 5 } & $\begin{array}{c}\text { Force } \\
\left(\times 10^{6} \mathrm{~N}\right)\end{array}$ & $\begin{array}{c}\text { Displacement } \\
(\mathrm{m})\end{array}$ & $\begin{array}{c}\text { Force } \\
\left(\times 10^{6} \mathrm{~N}\right)\end{array}$ & $\begin{array}{c}\text { Displacement } \\
(\mathrm{m})\end{array}$ \\
\hline $\mathrm{Y}$ & 15.79 & 0.011 & 4.98 & 0.001 \\
\hline $\mathrm{X}$ & 2.12 & 0.063 & 1.19 & 0.047 \\
\hline $\mathrm{Z}$ & 2.12 & 0.051 & 1.23 & 0.033 \\
\hline
\end{tabular}

lengths in the transversal and vertical directions were determined from the experimental data (Blessmann 1995).

In the TL, while the nodes of the towers may be assumed stationary, i.e. they experience negligibly small displacements, the nodal masses of the cables suffer large displacements, requiring the simulation of the velocity components at locations that are variable with time, thus greatly increasing the computational effort. Thus, to maintain the processing time within reasonable limits, the mean locations of all nodal masses along the conductors in the model of the TL segment were considered for determining the correlated velocity components. This simplifying hypothesis allowed the determination of the velocity components of the incident wind in a 2D rather than a $3 \mathrm{D}$ domain.

Then, the TL segment was contained in a plane, subdivided in a mesh composed by 150 rectangles laterally disposed, $100 \mathrm{~m}$ long in the horizontal direction and $50 \mathrm{~m}, 75 \mathrm{~m}$ and $100 \mathrm{~m}$ wide in the vertical direction. Following the procedure described before, wind velocity time histories were independently generated for each node of the 2D mesh and for each orientation $(x, y, z)$. These values were then used for determining the velocity components at the nodes of the structure, through the proposed interpolation procedure. The resulting spatially correlated wind field in the directions $(x, y, z)$, was used to evaluate the applied forces on each TL segment node (on towers, insulators and cables).

\subsection{Thunder Storms (TS) winds}

Ponte and Riera (2007) described a wind velocity field applicable to thunderstorm (TS) events, in which a descending flow occurs causing high-velocity and short duration winds near the ground surface. It was verified by Ponte and Riera (2010) that simulations of annual extreme wind velocities at meteorological stations in southern Brazil closely agree with existing records. Thus, the model may be used for design purposes in other regions, especially in cases with scarce or no data.

Available information suggests that the isokeraunic number in Oriximiná is higher than 120, i.e. almost twice the frequency observed in Brazilian temperate zones (centralsouth). It may be concluded that the tower GTS 01 will be subjected to a greater number of TS events than current design situations in Brazil, which imply a higher risk, since they are associated to larger velocities in a descending flow. However, considering additionally its geographical location and regional characteristics, the possibility of occurrence of the so called squall-lines was disregarded. On the other hand, stationary or quasi-stationary TS events were taken into account. In those events, the translational velocity of the cumulonimbus cloud is neglected in comparison with the wind velocity in the downdraft. The horizontal wind velocity evolution of these storms over time were simulated through the mentioned model, which considers the turbulent component described by a spectrum defined by a clipped white noise, between 0.05 and $0.55 \mathrm{~Hz}$. The normalized velocity for a maximum tangential velocity equal to $1.0 \mathrm{~m} / \mathrm{s}$ is shown in Figure 3. 


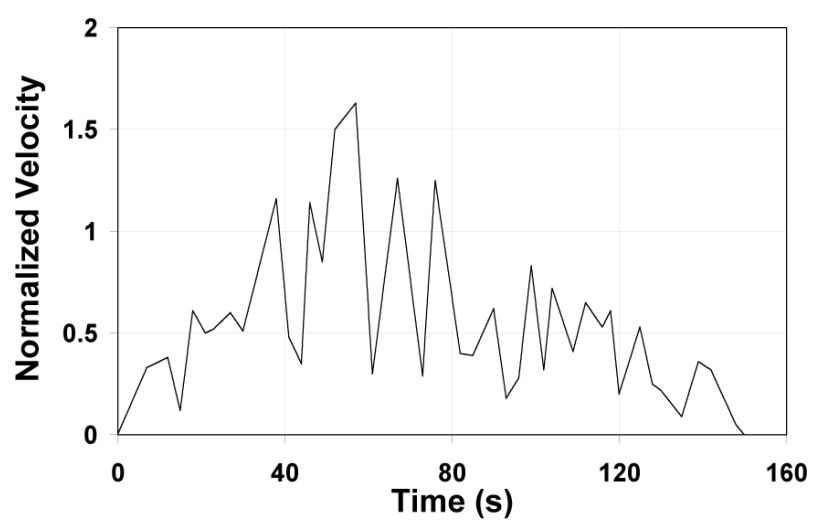

Fig. 3. Normalized tangential velocity in TS event

TS winds present an additional difficulty when compared to EPS winds. In the latter, the vertical wind velocity profile remains constant for any location on the surface. On the other hand, in TS events the wind velocity field depends on the position of the cumulonimbus cloud in relation to the location of interest. It was admitted, in consequence, that the horizontal velocity is maximum on the ground and decreases to $75 \%$ of this value at a $200 \mathrm{~m}$ height. The vertical component of the velocity was taken as $50 \%$ of the horizontal component. In a horizontal plane, the wind horizontal velocity reaches its maximum in the vertical plane which is coincident with the cumulonimbus cloud axis, rapidly decreasing with the distance. In order to simplify the 3D wind velocities field, a constant velocity was assumed within a $50 \mathrm{~m}$ horizontal range, being zero outside this region. Finally, a maximum horizontal velocity at ground level equal to $40 \mathrm{~m} / \mathrm{s}$ was adopted for design verification.

\section{Mechanical model for the dynamic analysis}

\subsection{Description of the numerical model}

The entire crossing over the Trombetas River was modelled, including the two highest towers (GTS 01 and GTS 02), conductor cables, shield wires, insulator strings and tower foundations, as shown in Figure 4. The insulator strings ( $7.15 \mathrm{~m}$ length) for each conductor cables bundle in the GTS towers are double (Fig. 5). The conductor cables used in the crossing section are bundles with four AACSR 535/240 cables while the shield wires are OPGW type. Their properties are presented in Table 3 and Table 4, respectively. In the model, the bundles were replaced by a single cable element, with outside diameter, cross section area, tension capacity and unit weight equal to four times the values presented in Table 3.

\subsection{Constitutive law of conductor cables and shield wires}

A linear model is used to calculate cables sags, elongations and tensions. At the beginning of the analysis (initial condition, $t=0 \mathrm{~s}$ ) the cable should be in a position such that, after the application of dead loads, it

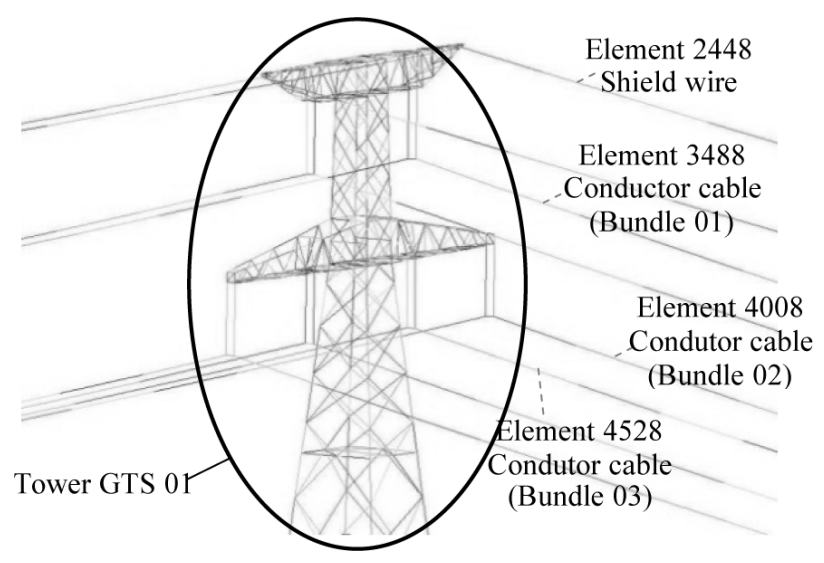

Fig. 5. Cable elements selected to break

Table 3. Properties of the AACSR 535/240 conductor cable

\begin{tabular}{lc}
\hline External diameter & $36.21 \mathrm{~mm}$ \\
\hline $\begin{array}{l}\text { Cross sectional area (aluminum } \\
\text { alloy) }\end{array}$ & $535.70 \mathrm{~mm}^{2}$ \\
\hline Cross sectional area (steel) & $239.36 \mathrm{~mm}^{2}$ \\
\hline Total cross sectional area & $775.06 \mathrm{~mm}^{2}$ \\
\hline Tension capacity & $499.5 \mathrm{kN}$ \\
\hline Weight per unit length & $34.64 \mathrm{~N} / \mathrm{m}$ \\
\hline Elastic modulus in tension & $94500 \mathrm{MPa}$ \\
\hline
\end{tabular}

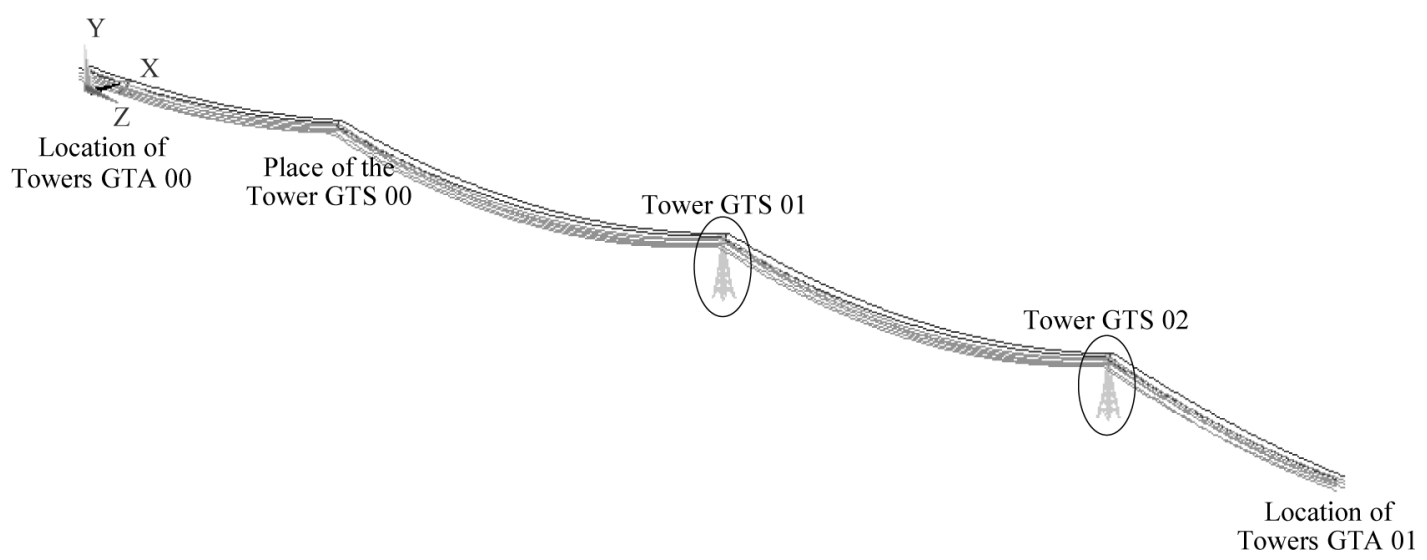

Fig. 4. Mechanical model of the crossing section over the Trombetas River 
Table 4. Properties of the OPGW shield wire

\begin{tabular}{ll}
\hline External diameter & $24.30 \mathrm{~mm}$ \\
\hline Cross sectional area & $349.14 \mathrm{~mm}^{2}$ \\
\hline Tension capacity & $397.6 \mathrm{kN}$ \\
\hline Weight per unit length & $22.563 \mathrm{~N} / \mathrm{m}$ \\
\hline Elastic modulus in tension & $129845 \mathrm{MPa}$ \\
\hline
\end{tabular}

is subjected to the design tension force, equivalent to a percentile of the tensile strength of the cable, with the theoretical catenary $\left(f_{\text {theoretical }}\right)$ and the maximum sag $\left(f_{e}\right)$. The formulation used to determine the theoretical catenary, the maximum sag, the position of the maximum sag $\left(x_{0}\right)$ and the theoretical length of the cables is described by Kaminski Jr. (2007). Additional details are given by Irvine and Caughey (1974).

\subsection{Constitutive law of insulator strings}

The insulator strings were modelled with elements able to carry only tensile forces. In this paper, a linear model is used. As mentioned before, all the insulator strings in the GTS towers are double with $7.15 \mathrm{~m}$ length. The values used to calculate the tensile forces in the insulator strings are presented in Table 5.

\subsection{Constitutive law of bars of the towers}

Towers GTS 01 and GTS 02 were designed for ASTM A572 steel, with elastic modulus $E=200 \mathrm{GPa}$. The linear model, both in tension as well as in compression, was adopted to describe the force-displacement behavior of the truss elements. The elastic modulus of ASTM A572 steel was adopted as $E_{B T}=200 \times 10^{3} \mathrm{MPa}$.

\subsection{Load application}

The required duration of the dynamic analysis depends on the applied loading; for cable rupture the numerical integration extended to $40 \mathrm{~s}$, while for EPS and TS wind loads the duration of the analysis was $60 \mathrm{~s}$ and $160 \mathrm{~s}$, respectively. The dead weight of cables, towers, insulators and additional masses was gradually applied during $5 \mathrm{~s}$, allowing $15 \mathrm{~s}$ to damp out induced vibrations.

Rupture of the cable is specified to occur $20 \mathrm{~s}$ after beginning the integration process, that is, after the initial conditions are reached. The cable rupture is simulated making the axial force in the element selected to break equal to zero. The cable elements (conductor cable bundle and shield wire) assumed to break is shown in Figure 5.

EPS wind forces were instantaneously applied $(0.1 \mathrm{~s}$ during $50 \mathrm{~s}$ ) at each node of the TL segment model. TS wind forces were applied after $10 \mathrm{~s}$. The simulation

Table 5. Properties of insulator strings

\begin{tabular}{ll}
\hline Cross sectional area & $1000 \mathrm{~mm}^{2}$ \\
\hline Weight for meter of two insulators strings & $933.0 \mathrm{~N} / \mathrm{m}$ \\
\hline Elastic modulus in tension & $200000 \mathrm{MPa}$ \\
\hline
\end{tabular}

continues until the end of the TS event, resulting in a total duration of the analysis of $160 \mathrm{~s}$.

\section{Results, comparisons and discussions}

The evolution with time of the displacements in longitudinal direction ( $z$ axis) of nodes 19 and 148, located at top and bottom of tower GTS 01, respectively, due to rupture of conductor cable bundle 01 , for the three support conditions, are shown in Figure 7.

The axial forces in some selected diagonal and main members of tower GTS 01 (Fig. 6), for the standard static analysis due to rupture of conductor cable bundle 01 , are indicated in Table 6, along with the peak values and final state predicted by the dynamic analysis. Table 6 shows that the peak values of axial forces according to the dynamic analysis for the cable rupture hypothesis were, on average, two times higher than those obtained in the standard static analysis.

This leads to important conclusions. Firstly, it may be pointed out that the dynamic analysis of the models on rigid and flexible (according to actual design) foundations led to almost coincident peak values and final state values for axial forces on the selected elements, while the response for the model on a floating foundation tended to be slightly lower. In addition, the close correlation between the final state in the dynamic analysis and the standard static predictions constitutes strong evidence of the robustness of the latter, which is normally adopted for engineering design. On the other hand, dynamic amplification may approach $50 \%$ for main members and significantly exceed that value in case of diagonal members. It is thus concluded that dynamic amplification effects are not negligible in TL crossings and may cause failure of the towers if not properly taken into account for design purposes.

The evolution with of displacements in the direction normal to the TL of nodes 19 and 148 (Fig. 6) due to EPS wind loads for the three support types analyzed are shown in Figure 8.

Axial forces in selected diagonal and main members of the tower obtained by means of the static and dynamic analysis for EPS wind loads are indicated in Table 7. The maximum axial force values in structural members are determined by Eqn (2):

$$
F_{\max }=\mu_{F}\left(1+g C V_{F}\right)
$$

in which $\mu_{F}$ denotes the mean value of the axial force $F(\mathrm{t})$ over part of the time of analysis (from $40 \mathrm{~s}$ to $60 \mathrm{~s}$ ), $C V_{F}$ is the coefficient of variation and $g$ represents a peak factor taken herein equal to 4 . The maximum values provided by the dynamic analysis, for the three support conditions, were around $20 \%$ lower than those obtained in the static analysis, indicating that the static equivalent procedure adopted by TL design codes is appropriate even for structures outside the intended range of applicability of the latter. 


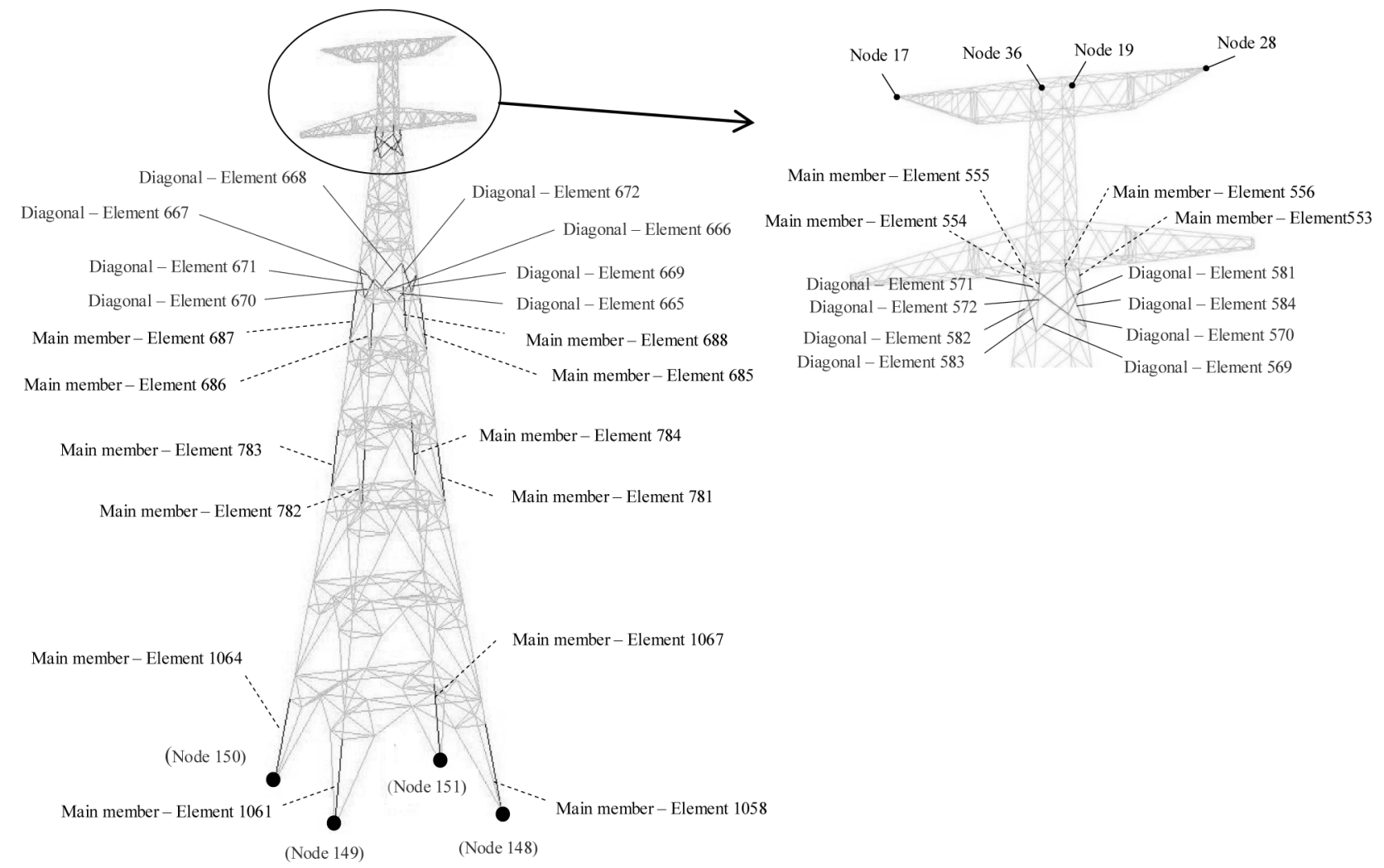

Fig. 6. Selected diagonal and main members of the inferior part of the tower GTS 01
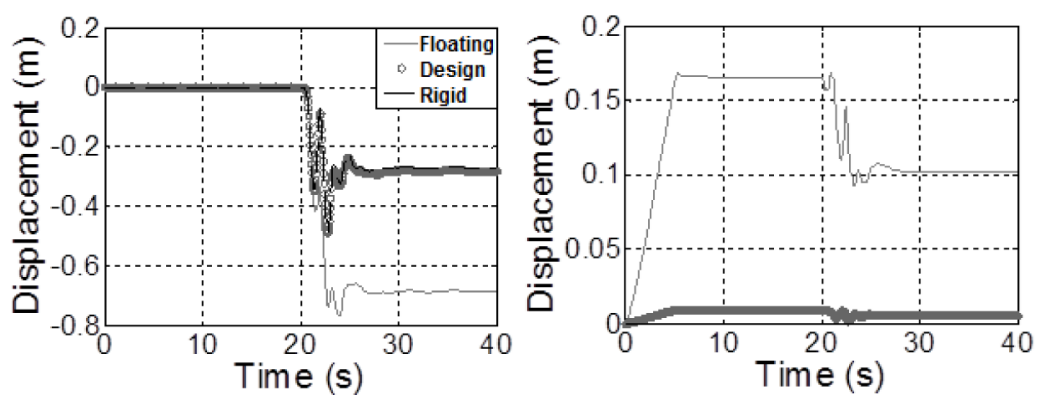

Fig. 7. Displacements in the longitudinal direction at top (Node 19 - left) and at bottom (Node 148 - right) of tower GTS 01 , due to rupture of conductor cable bundle 01 , for the three support types considered

The evolution with time of displacements in the direction normal to the TL of nodes 19 and 148 (Fig. 6) due to TS wind loads for the three support types analyzed are shown in Figure 9.

The axial forces in selected diagonal and main members of the tower for the static and dynamic analysis due to TS wind loads are indicated in Table 8. Peak values predicted by the dynamic analysis, for the three support conditions, were higher than those obtained in the static analysis, for almost all bars, except the main member 1067. Additionally, the rigid and the design supports in the dynamic analysis, presented practically coincident peak values for axial forces on the selected elements, while the responses for the floating foundation were slightly higher.
It is also important to point out that great variability was observed on the axial forces determined in the static and dynamic analysis. This may be explained by the fact that there is not an agreement of a method, in current engineering design, to determine TS wind loads. Engineers usually adopt a very simple model based on practical experience, which applies a constant force along the tower height, caused by a wind velocity that is $20 \%$ higher than the EPS reference wind speed (10 $\mathrm{m}$ above ground). In addition, wind forces on cables are determined considering $50 \%$ of the EPS reference wind speed. Furthermore, this model is adopted even in TL structures located in regions that are prone to the occurrence of squall-lines, which could explain the high rate of accidents suffered by TL tower structures. 
Table 6. Axial forces in some members of the tower GTS 01 due to rupture of the conductor cable bundle 01

\begin{tabular}{|c|c|c|c|c|c|c|c|}
\hline \multirow{3}{*}{ Node } & \multirow{3}{*}{$\begin{array}{c}\text { Static } \\
\text { Analysis } \\
(\mathrm{kN})\end{array}$} & \multicolumn{6}{|c|}{ Dynamic Analysis } \\
\hline & & \multicolumn{2}{|c|}{ Rigid Foundation } & \multicolumn{2}{|c|}{ Design Foundation } & \multicolumn{2}{|c|}{ Floating Foundation } \\
\hline & & $\begin{array}{c}\text { Peak } \\
\text { Response } \\
(\mathrm{kN})\end{array}$ & $\begin{array}{c}\text { Final state } \\
\text { Response } \\
(\mathrm{kN})\end{array}$ & $\begin{array}{c}\text { Peak } \\
\text { Response } \\
(\mathrm{kN})\end{array}$ & $\begin{array}{c}\text { Final state } \\
\text { Response } \\
(\mathrm{kN})\end{array}$ & $\begin{array}{c}\text { Peak } \\
\text { Response } \\
(\mathrm{kN})\end{array}$ & $\begin{array}{c}\text { Final state } \\
\text { Response } \\
(\mathrm{kN})\end{array}$ \\
\hline 553 & 288 & 660 & 299 & 633 & 298 & 492 & 279 \\
\hline 554 & 40 & 518 & 53 & 489 & 52 & 322 & 32 \\
\hline 555 & -1288 & -1670 & -1318 & -1644 & -1317 & -1511 & -1297 \\
\hline 556 & -1121 & -1665 & -1160 & -1635 & -1159 & -1505 & -1138 \\
\hline 685 & 127 & 720 & 142 & 656 & 140 & 339 & 93 \\
\hline 686 & 50 & 747 & 68 & 681 & 65 & 324 & 18 \\
\hline 687 & -1599 & -2222 & -1633 & -2160 & -1631 & -1845 & -1582 \\
\hline 688 & -1532 & -2274 & -1568 & -2194 & -1566 & -1829 & -1518 \\
\hline 569 & 217 & 371 & 215 & 373 & 215 & 372 & 216 \\
\hline 570 & -204 & -372 & -204 & -374 & -204 & -369 & -204 \\
\hline 571 & 192 & 382 & 185 & 359 & 185 & 355 & 186 \\
\hline 572 & -184 & -375 & -189 & -377 & -189 & -370 & -189 \\
\hline 581 & -210 & -383 & -209 & -378 & -209 & -358 & -205 \\
\hline 582 & 184 & 352 & 183 & 358 & 183 & 369 & 189 \\
\hline 583 & -156 & -321 & -154 & -330 & -154 & -338 & -159 \\
\hline 584 & 229 & 409 & 229 & 403 & 228 & 380 & 224 \\
\hline
\end{tabular}
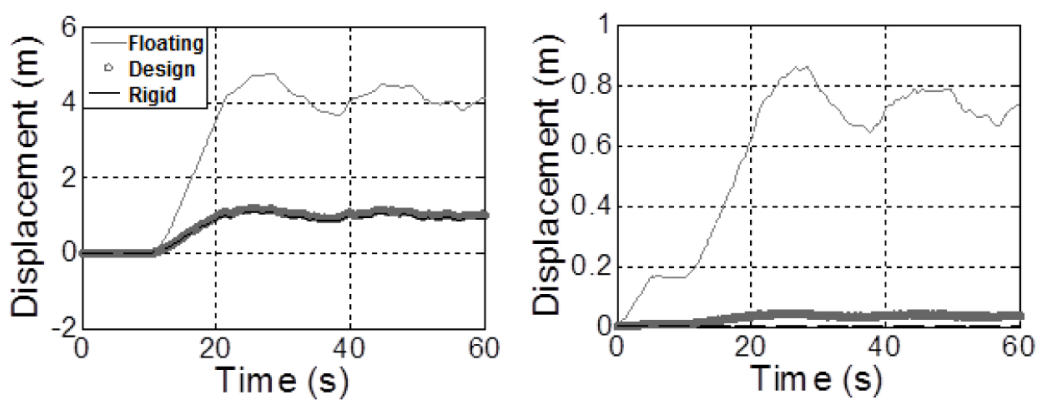

Fig. 8. Displacements in the direction normal to the TL at top (Node 19 - left) and bottom (Node 148 - right) of tower GTS 01 , due to EPS wind load, for three support types considered

Table 7. Axial forces in some members of the tower GTS 01 due to EPS wind loads

\begin{tabular}{llcccccc}
\hline Node & 571 & 572 & 686 & 688 & 1064 & 1067 \\
\hline Static Analysis $(\mathrm{kN})$ & -491 & 489 & 4202 & -5904 & 4476 & -7903 \\
\hline \multirow{5}{*}{ Rigid Foundation } & & & & & & \\
\cline { 2 - 8 } & Peak $(\mathrm{kN})$ & -405 & 411 & 2997 & -4557 & 4314 & -6363 \\
\cline { 2 - 8 } & Mean $(\mathrm{kN})$ & -336 & 342 & 2473 & -4051 & 2970 & -5807 \\
\cline { 2 - 8 } $\begin{array}{l}\text { Dynamic } \\
\text { Analysis }\end{array}$ & Design Foundation & & & & & & \\
\cline { 2 - 8 } & Peak $(\mathrm{kN})$ & -405 & 411 & 2996 & -4560 & 4340 & -6399 \\
\cline { 2 - 8 } & Mean $(\mathrm{kN})$ & -437 & 343 & 2473 & -4055 & 2986 & -5827 \\
\cline { 2 - 8 } & Floating Foundation & & & & & & \\
\cline { 2 - 8 } & Peak $(\mathrm{kN})$ & -341 & 347 & 2553 & -4115 & 3075 & -5986 \\
\cline { 2 - 7 } & Mean $(\mathrm{kN})$ & & & & &
\end{tabular}



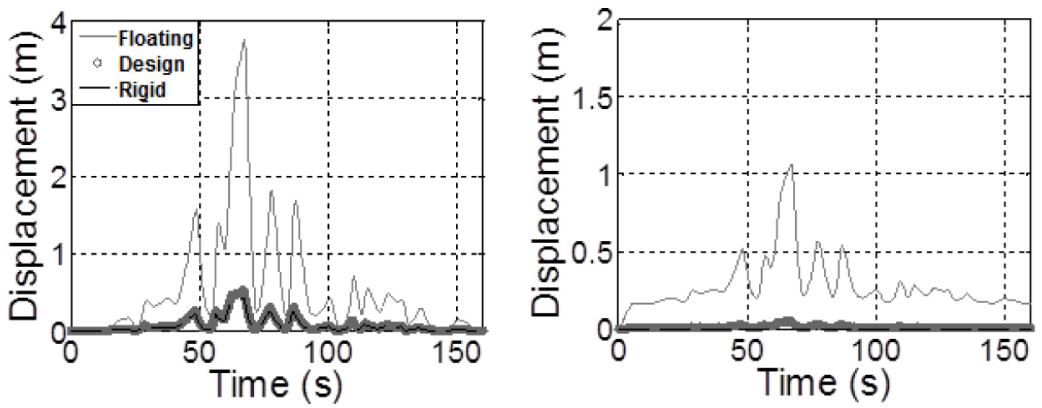

Fig. 9. Displacements in the direction normal to the TL at top (Node 19 - left) and bottom (Node 148 - right) of tower GTS 01 , due to TS wind load, for three support types considered

Table 8. Axial forces in some members of the tower GTS 01 due to TS wind loads

\begin{tabular}{llcccccc}
\hline Node & 571 & 572 & 686 & 688 & 1064 & 1067 \\
\hline Static Analysis (kN) & -188 & 190 & 1277 & -2938 & 1515 & -4933 \\
\hline & Rigid Foundation & & & & & & \\
\cline { 2 - 8 } & Peak (kN) & -115 & 126 & 427 & -2521 & 527 & -5527 \\
\cline { 2 - 8 } $\begin{array}{l}\text { Dynamic } \\
\text { Analysis }\end{array}$ & Design Foundation & & & & & & \\
\cline { 2 - 8 } & Peak (kN) & -116 & 126 & 442 & -2521 & 545 & -5537 \\
\cline { 2 - 8 } & Floating Foundation & & & & & & \\
\cline { 2 - 8 } & Peak (kN) & -128 & 138 & 728 & -2661 & 963 & -5579 \\
\hline
\end{tabular}

\section{Conclusions}

This paper describes the dynamic analysis of a four spans section of a TL crossing over the Trombetas River, in the Amazon region, which includes two $190 \mathrm{~m}$-high TL steel towers, subjected to EPS and TS wind loads as well as to cable rupture. The entire TL segment was modelled, including the two highest towers and all other elements: foundations, conductors, shield cables and insulator strings. The computed dynamic response of tower GTS 01 was then compared with the static response obtained by standard codes procedures.

In the cable rupture analysis, since the latter aim at determining forces and displacements after the rupture has occurred, the close correlation of the final state in the dynamic analysis with the standard static predictions constitutes strong evidence of the robustness of the static equivalent model. On the other hand, dynamic amplification may approach $50 \%$ for main members and significantly exceed that value in case of diagonal members. It is thus concluded that dynamic amplification effects are not negligible in TL crossings and may cause failure of the towers if not properly taken into account for design purposes.

For EPS wind loads, the peak values provided by dynamic analysis, were around $20 \%$ lower than those obtained in the static analysis, indicating that the static equivalent procedure adopted by TL design codes is appropriate even for structures outside the range of its scope. Part of it could be explained due to the adoption of a gust coefficient corresponding to $800 \mathrm{~m}$ span, for the determination of the forces acting on cables in the static analysis, which tends to be conservative, since spatial correlation has considerable influence on the forces along cables and towers.

On the TS wind load analysis, it was verified a great variability on the axial forces due to the static and dynamic analysis. This may be explained by the fact that engineers usually adopt a very simple model based on practical experience, even in TL structures located in regions that are prone to the occurrence of squall-lines, which explains some accidents that happened to tower structures. Thus, further research in this subject is highly needed and it is currently in progress by the authors.

\section{References}

Alam, M. J.; Santhakumar, A. R. 1994. Probabilistic wind loadings on transmission line structures in India, Engineering Structures 16(3): 181-189. http://dx.doi.org/10.1016/0141-0296(94)90076-0

Blessmann, J. 1995. O vento na engenharia estrutural. EDUFRGS, Brazil (in Portuguese).

Davenport, A. G. 1961. The spectrum of horizontal gustiness near the ground in high winds, Quarterly Journal of the Royal Meteorological Society 87: 194-211. http://dx.doi.org/10.1002/qj.49708737208

IEC 60826:2003 - Design criteria of overhead transmission line. IEC - International Electrotechnical Commission, 2003. 
Irvine, H. M.; Caughey, T. K. 1974. The linear theory of free vibrations of a suspended cable, in Proceedings of the Royal Society of London A341 1974, 10 December 1974, 341(1626): 299-315. http://dx.doi.org/10.1098/rspa.1974.0189

Kaminski Jr., J.; Miguel, L. F. F.; Menezes, R. C. R. 2005. Aspectos relevantes na análise dinâmica de torres de LT submetidas à ruptura de cabos, in XVIII SNPTEE - XVIII Seminário Nacional de Produção e Transmissão de Energia Elétrica, 16-21 October 2005, Brazil (in Portuguese).

Kaminski Jr., J. 2007. Incertezas de modelo na análise de torres metálicas treliçadas de linhas de transmissão: Doctoral Thesis. Federal University of Rio Grande do Sul, Brazil (in Portuguese).

Kaminski Jr., J.; Riera, J. D.; Menezes, R. C. R.; Miguel, L. F. F. 2008. Model uncertainty in the assessment of transmission line towers subjected to cable rupture, Engineering Structures 30: 2935-2944.

http://dx.doi.org/10.1016/j.engstruct.2008.03.011

Kudzys, A. 2006. Safety of power transmission line structures under wind and ice storms, Engineering Structures 28(5): 682-689.

http://dx.doi.org/10.1016/j.engstruct.2005.09.026

Li, C. Q. 2000. A stochastic model of severe thunderstorms for transmission line design, Probabilistic Engineering Mechanics 15(4): 359-364. http://dx.doi.org/10.1016/S0266-8920(99)00037-5

Lin, W. E.; Savory, E.; McIntyre, R. P.; Vandelaar, C. S.; King, J. P. C. 2012. The response of an overhead electrical power transmission line to two types of wind forcing, Journal of Wind Engineering and Industrial Aerodynamics 100: 58-69. http://dx.doi.org/10.1016/j.jweia.2011.10.005

Loredo-Souza, A. M.; Davenport, A. G. 2003. The influence of the design methodology in the response of transmission towers to wind loading, Journal of Wind Engineering and Industrial Aerodynamics 91(8): 995-1005. http://dx.doi.org/10.1016/S0167-6105(03)00048-5

Matheson, M. J.; Holmes, J. D. 1981. Simulation of the dynamic response of transmission lines in strong winds, Engineering Structures 3(2): 105-110. http://dx.doi.org/10.1016/0141-0296(81)90036-5

Menezes, R. C. R.; Riera, J. D.; Fadel Miguel, L. F.; Kaminski Jr, J.; Miguel, L. F. F.; Ferreira da Silva, J. B. G. 2012. On modeling the dynamic response of a $190 \mathrm{~m}$ high TL tower for large river crossing in the Brasilian Amazon region, in CIGRÉ Annual Meeting, 26-21 August 2012, Paris, France.

Miguel, L. F. F.; Menezes, R. C. R.; Kaminski Jr., J. 2005. Sobre a resposta de estruturas de LT submetidas a cargas dinâmicas, in XI Encontro Ibero-americano do CIGRE - ERIAC 2005, Paraguay (in Portuguese).

Miguel, L. F. F.; Fadel Miguel, L. F.; Kaminski Jr., J.; Riera, J. D.; Menezes, R. C. R. 2009. Model uncertainty in the assessment of EPS wind loads in transmission line design, in Proceedings of the International Seminar on Modeling and Identification of Structures Subjected to Dynamic Excitation - Emphasis on Transmission Lines, 01-02 September 2009, Brazil.
Miguel, L. F. F.; Fadel Miguel, L. F.; Kaminski Jr., J.; Riera, J. D.; Menezes, R. C. R. 2012. Assessment of code recommendations through simulation of EPS wind loads along a segment of a transmission line, Engineering Structures 43: 1-11.

http://dx.doi.org/10.1016/j.engstruct.2012.05.004

Paluch, M.; Cappellari, J. T. T. O.; Riera, J. D. 2007. Experimental and numerical assessment of EPS wind action on long span transmission line conductors, Journal of Wind Engineering Industrial Aerodynamics 95(7): 473-492. http://dx.doi.org/10.1016/j.jweia.2006.09.003

Ponte, J.; Riera, J. D. 2007. Wind velocity field during thunderstorms, Wind and Structures 10: 287-300. http://dx.doi.org/10.12989/was.2007.10.3.287

Ponte, J.; Riera, J. D. 2010. Simulation of extreme wind series caused by thunderstorms in temperate latitudes, Structural Safety 32: 231-237.

http://dx.doi.org/10.1016/j.strusafe.2010.02.002

Riera, J. D.; Ambrosini, R. D. 1992. Analysis of structures subjected to random loading using the transfer matrix or numerical integration methods, Engineering Structures 14(3): 176-179. http://dx.doi.org/10.1016/0141-0296(92)90028-O

Oliver, S. E.; Moriarty, W. W.; Holmes, J. D. 2000. A risk model for design of transmission line systems against thunderstorm downburst winds, Engineering Structures 22(9): 1173-1179. http://dx.doi.org/10.1016/S0141-0296(99)00057-7

Savory, E.; Parke, G. A. R.; Zeinoddini, M.; Toy, N.; Disney, P. 2001. Modelling of tornado and microburst-induced wind loading and failure of a lattice transmission tower, Engineering Structures 23(4): 365-375. http://dx.doi.org/10.1016/S0141-0296(00)00045-6

Savory, E.; Parke, G. A. R.; Disney, P.; Toy, N. 2008. Wind-induced transmission tower foundation loads: a field studydesign code comparison, Journal of Wind Engineering Industrial Aerodynamics 96: 1103-1110. http://dx.doi.org/10.1016/j.jweia.2007.06.033

Shehata, A. Y.; Damatty, A. A.; Savory, E. 2005. Finite element modeling of transmission line under downburst wind loading, Finite Elements in Analysis and Design 42: 71-89. http://dx.doi.org/10.1016/j.finel.2005.05.005

Shinozuka, M.; Jan, C. M. 1972. Digital simulation of random process and its applications, Journal of Sound and Vibration 25: 111-118. http://dx.doi.org/10.1016/0022-460X(72)90600-1

Silva, V. R.; Riera, J. D.; Blessman, J.; Nanni, J. F.; Galindez, E. 1984. Determinação experimental das propriedades dinâmicas básicas de uma torre de transmissão de $230 \mathrm{kV}$, in VII SNPTEE - VII Seminário Nacional de Produção e Transmissão de Energia Elétrica, 02-06 December 1984, Brazil (in Portuguese).

Silva, J. G. S.; Vellasco, P. C. G.; Andrade, S. S. A. L.; Oliveira, M. I. R. 2005. Structural assessment of current steel design models for transmission and telecommunication towers, Journal of Constructional Steel Research 61: 1108-1134. http://dx.doi.org/10.1016/j.jcsr.2005.02.009

Leandro Fleck FADEL MIGUEL. He obtained the degree of Civil Engineer in 2001. He received MSc and DSc degrees in Civil Engineering in 2003 and 2007, both from the Federal University of Rio Grande do Sul (UFRGS), Porto Alegre, Brazil. He entered the teaching staff of the Department of Civil Engineering of the Federal University of Santa Catarina (UFSC) in 2010, becoming Adjunct Professor and shortly afterwards Professor of the Postgraduate Program in Civil Engineering (PPGEC/UFSC). He has published about 20 papers in international Journals in the fields of structural dynamics, vibrations and structural engineering. 
João KAMINSKI Jr. He obtained the degree of Civil Engineer in 1992. He received MSc and DSc degrees in Civil Engineering in 1996 and 2007, both from the Federal University of Rio Grande do Sul (UFRGS), Porto Alegre, Brazil. He entered the teaching staff of the Department of Civil Engineering of the Federal University of Santa Maria (UFSM) in 1996, becoming Adjunct Professor. Since 2007 he is member of the permanent teaching staff of the Postgraduate Program in Civil Engineering (PPGEC/UFSM). He has published about 5 papers in international Journals in the fields of structural dynamics, vibrations and structural engineering.

Letícia Fleck Fadel MIGUEL. She obtained the degree of Civil Engineer in 1999 with Academic Distinction. She received MSc and DSc degrees in Civil Engineering in 2002 and 2005, both from the Federal University of Rio Grande do Sul (UFRGS), Porto Alegre, Brazil. She entered the teaching staff of the Department of Mechanical Engineering (UFRGS) in 2005, becoming Adjunct Professor in 2007 and shortly afterwards Professor of the Postgraduate Program in Mechanical Engineering (PROMEC/UFRGS). She is a researcher of Brazil's National Research Council (CNPq). She has published about 26 papers in international Journals in the fields of Structural Dynamics, Vibrations and Structural Engineering.

Jorge Daniel RIERA. He obtained a degree of Civil Engineer at the Universidad Nacional de Tucumán (UNT), Argentina, in 1963 and the degrees of MSc and PhD in Engineering at Princeton University, NJ, USA, in 1965 and 1968, respectively. He was a Research Engineer at Gilbert Commonwealth, Inc., USA with activities related to nuclear power plant (NPP) structural design until 1970, when he accepted the position of Associate Professor at UNT. In 1976 he became Full Professor of the Universidade Federal do Rio Grande do Sul, Porto Alegre, Brazil, where he now holds the position of Invited Professor. He is member of the Academia Brasileira de Ciências, the Academia Nacional de Ciencias and Academia Nacional de Ingeniería (Argentina) and author of more than a hundred papers published in international journals or proceedings of scientific events in the áreas of structural engineering and reliability, with emphasis in structural dynamics, seismic and wind engineering, and nuclear power plant structures.

Ruy Carlos Ramos de MENEZES. He obtained the degree of Civil Engineer in 1981 and the degree of Electrical Engineer in 1984 at the Federal University of Rio Grande do Sul (UFRGS), Porto Alegre, Brazil. He received MSc degree in Civil Engineering in 1988 from UFRGS and the Dr techn. degree in 1992 at the University of Innsbruck, Austria. Since 1994, he is Professor of the Department of Civil Engineering at UFRGS and member of the Postgraduate Program in Civil Engineering. His main area of interest is Reliability Based Design connect to Transmission Lines. He is chairman of the Brazilian Study Committee on Transmission Lines of CIGRE (International Council on Large Power Systems) and research member of the Brazilian National Research Council (CNPq). 